\title{
The Research of the Present Situation of the Disabled Sports Competitions in China Basing on Time Series
}

\author{
Hong Luo*
}

Sports Teaching and Research Section, Fuyang Vocational and Technical College, Fuyang 236031, Anhui, China

\begin{abstract}
In the view that, the projects Chinese disabled people had participated in Paralympics are less, the number of entries and as well as the experience are also less than others, however, much of our competitors are people of a new type. Facing on the so called "more less than 3, more than 1 " problems, this paper uses time series analysis, and then concludes that Chinese cities disabled athletes people, places and the number of the national fitness rehabilitation projects of provincial level rise over time, and municipal activities present a circulation and seasonal changes over time. Therefore, we need to strengthen the management of the activities places of municipal disabled people, to make it better serve the disabled, and then optimize management mode of the Chinese disabled people's sports competition, and make it better manage local disabled peoples' federation.
\end{abstract}

Keywords: Competition management, disabled, mathematical model, paralympics games, time series.

\section{INTRODUCTION}

At present, the number of Chinese disabled people is more than eighty millions, so our country became the largest number of people with disabilities around the world. Participating in sports of the disabled people can not only adjust their psychology and emotion, but also make the best rehabilitation for the disabled, as well as giving them a platform to show their unyielding spirit to the whole society. Participating in the competitive sports projects for the disabled people can their value and position, at the same time, it also makes more disabled people to participate in the sports games [1]. Chinese government improves the satisfaction of the Chinese public through the development of sports for the disabled [2]. Comparing with western developed countries, the development of competitive sports for the disabled in China started relatively late, so the foundation is still very weak, which leads to the situations that the projects, the number of entries, and the inexperienced joining are all less than others in Paralympics, and the much of the competitors are new athletes, so called " more less than 3, more than 1 " status quo [3].

The 2008 Beijing Paralympics games achieved a successful leap of Chinese sports undertakings for the disabled people, the Chinese Paralympics athletes performances are outstanding, the achievements are ideal, these reflect the constant increase of the development level of China's sports for the disabled from the side, it sounds like a fable that the disabled can play basketball [4].

But today, in the Paralympics flexible movement of the basketball players really let us admire. Under the condition of controlling the wheelchair, they have get the line dribbling, turn around, and even shot, all of the actions, are of an organized effort, which makes people surprised [5]. In Beijing Paralympics games, there is a classic basketball games for the disabled is that United States played against Canada. In the normal competition, there must be no suspense; the U.S. male basketball team would certainly sweeping trounced the Canada. But in the real Paralympics game, Canada team 's character, who is known as the "wheelchair Jordan", helped to increase the overall strength of Canada, and the United States played two overtime, in the end, the Canadian team had finally entered the final victory over the United States. There were no losers in the game, they were doing their best, the audience of the game was also very satisfied, and really enjoyed the process more than the result. Here, I want to give my sincere regards and respect to those brave disabled athletes [6].

For this, we should make the analysis of the situation that Chinese disabled people's participating in sports, and carry on the time series analysis of some of the statistical data, then it is concluded that the development situation of Chinese sports of the disabled, and give reasonable suggestions.

\section{THE ESTABLISHMENT OF THE MODEL}

For time series analysis, this article is in accordance with the time changes to list events down successively, and constitutes an analysis of time series. We make an observation and study of time series effectively, then find out its corresponding change and law of development, finally we predict that its future trend is corresponding to the time series analysis.

First, we need understand the following model for time series analysis.

1) Mode AR(p): 


$$
\left\{\begin{array}{l}
x_{t}=\Phi_{0}+\Phi_{1} x_{t-1}+\Phi_{2} x_{t-2}+\ldots+\Phi_{p} x_{t-p}+\varepsilon_{t} \\
\Phi_{p} \neq 0 \\
E\left(\varepsilon_{t}\right)=0 \quad \operatorname{Var}\left(\varepsilon_{t}\right)=\sigma_{\delta}^{2}, E\left(\varepsilon_{t} \varepsilon_{s}\right)=0, s \neq t \\
E x_{s} \varepsilon_{t}=0, \forall s<t
\end{array}\right.
$$

The mode of the above structure is called auto-regressive model of $\mathrm{p}$ order, recorded as $\mathrm{AR}(\mathrm{p})$.

Mode $\operatorname{MA}(q)$ :

$$
\left\{\begin{array}{l}
x_{t}=u+\varepsilon_{t}-\theta_{1} \varepsilon_{t-1}-\theta_{2} \varepsilon_{t-2}-\ldots-\theta_{q} \varepsilon_{t-q} \\
\theta_{q} \neq 0 \\
E\left(\varepsilon_{t}\right)=0, \operatorname{Var}\left(\varepsilon_{t}\right)=\sigma_{\delta}^{2}, E\left(\varepsilon_{t} \varepsilon_{s}\right)=0, s \neq t
\end{array}\right.
$$

The mode of the above structure is called auto-regressive model of q, recorded as MA(q).

Mode $\operatorname{ARMA}(\mathrm{p}, \mathrm{q})$ :

$$
\left\{\begin{array}{l}
x_{t}=\Phi_{0}+\Phi_{1} x_{t-1}+\Phi_{2} x_{t-2}+\ldots+\Phi_{p} x_{t-p}+\varepsilon_{t}-\theta_{1} \varepsilon_{t-1}-\theta_{2} \varepsilon_{t-2}-\ldots-\theta_{q} \varepsilon_{t-q} \\
\Phi_{p} \neq 0, \theta_{q} \neq 0 \\
E\left(\varepsilon_{t}\right)=0 \quad \operatorname{Var}\left(\varepsilon_{t}\right)=\sigma_{\delta}^{2}, E\left(\varepsilon_{t} \varepsilon_{s}\right)=0, s \neq t \\
E x_{s} \varepsilon_{t}=0, \forall s<t
\end{array}\right.
$$

The mode of the above structure is called auto-regressive model of $\mathrm{p} q$, recorded as $\operatorname{ARMA}(\mathrm{p}, \mathrm{q})$.

\subsection{Modeling of Stationary Series}

(1) The process:

According to the number of volleyball papers in the sports core journals from 2008-2013this 6 years, we list the initial data of the following process (The correlation coefficient calculation sample), (Model identification), (Estimating numbers), (Model test), (Model optimizing), (Series forecast) like Fig. (1) (Model process).

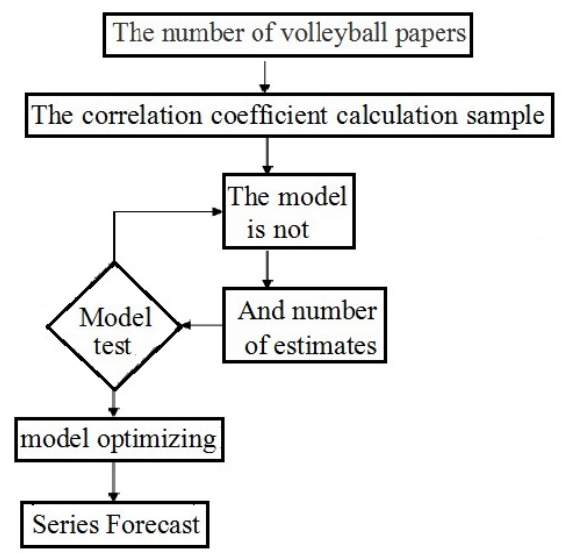

Fig. (1). Model of the process.

(2) Calculate the correlation coefficient of the sample: Sample autocorrelation coefficient:

$$
\hat{\rho}_{k}=\frac{\sum_{t=1}^{n-k}\left(x_{t}-\bar{x}\right)\left(x_{t+k}-\bar{x}\right)}{\sum_{t=1}^{n}\left(x_{t}-\bar{x}\right)^{2}}
$$

Partial autocorrelation coefficient of samples:

$$
\hat{\Phi}_{k k}=\frac{\hat{D}_{k}}{\hat{D}}
$$

(3) Model identification (like Table 1):

Table 1. The basic principle.

\begin{tabular}{|c|c|c|}
\hline$\hat{\rho}_{k}$ & $\hat{\Phi}_{k k}$ & \\
\hline \hline Motion trail & Motion trail of p order & $\operatorname{AR}(\mathrm{p})$ \\
\hline Motion trail of q order & Motion trail & $\operatorname{MA}(\mathrm{q})$ \\
\hline Motion trail & Motion trail & $\operatorname{ARMA}(\mathrm{p}, \mathrm{q})$ \\
\hline
\end{tabular}

(4) The approximate distribution of the sample correlation coefficient:

Barlett: $\hat{\rho}_{k} \sim N\left(0, \frac{1}{n}\right), n \rightarrow \infty$

Quenouille: $\hat{\Phi}_{k k} \sim N\left(0, \frac{1}{n}\right), n \rightarrow \infty$

(5) Parameter estimation:

solve-for parameter is $p+q+2$ The commonly estimating method of unknown parameters is:Torque estimation, the maximum estimation, and significant test of mode 6 .

Purpose: test the validity of the model (to extract the sufficient of the information)

Inspection objects: the residual sequence

Judging principle: a good fitting model should be able to extract the sample observations in the sequence of related information, the residual sequence can discuss the data, and on the other hand, it needs to points the condition.

The original assumption: The number of volleyball papers on sports core journals.

$$
H_{0} \text { о } \rho_{1}=\rho_{2}=\ldots=\rho_{m}=0, \forall m \geq 1
$$

The alternative hypothesis: the corresponding residual is the differential data that need to be discussed.

$$
H_{1} \circ \rho_{k} \neq 0, \forall m \geq 1, k \leq m
$$

test statistics:

LB statistics:

$$
L B=n(n+2) \sum_{k=1}^{m}\left(\frac{\hat{\rho}_{k}^{2}}{n-k}\right) \sim \chi^{2}(m)
$$

Parametric test of significance

Purpose: test each of the corresponding unknown parameter value is whether nonzero or not, delete the dominant parameter.

$$
\begin{aligned}
& H_{0}: \beta_{j}=0 \quad H_{1}: \beta_{j} \neq 0 \\
& \text { test statistics: } T=\sqrt{n-m} \frac{\hat{\beta}_{j}-\beta_{j}}{\sqrt{a_{j j} Q(\widetilde{\beta})}} \sim t(n-m)
\end{aligned}
$$




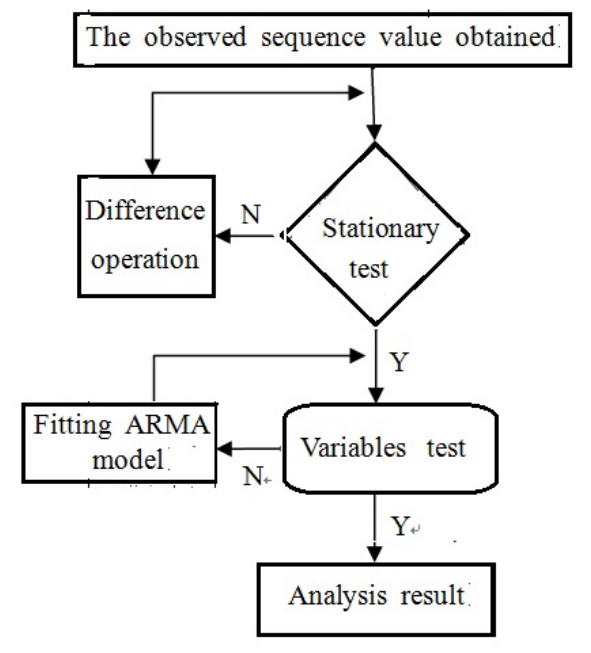

Fig. (2). Non stationary sequence modelling flowchart.

\section{Model optimization:}

Questions: here, we assume that the model passed the corresponding inspection, it means the data is on a certain feasible range, this model can effectively draw the results of the corresponding optimization

Purpose: select the relatively optimal model.

Sequence prediction:

Linear prediction function: $x_{t}=\sum_{i=0}^{\infty} C_{i} x_{t-1-i}$

Variance minimum principle: $\operatorname{Var}_{\hat{x}_{(t)}}\left[e_{t}(l)\right]=\min \left\{\operatorname{Var}\left[e_{t}(l)\right]\right\}$

as the factors of the following model analysis.

Non-stationary sequence modeling. First we need the smooth operation of the data, then establish the model $\operatorname{ARIMA}(p, q)$ and calculate it by the model, we introduce the mode in the following:

The using occasions of the model structure is fitting difference stationary series.

Model structure:

$$
\left\{\begin{array}{l}
\Phi(B) \nabla^{d} x_{t}=\Theta(B) \varepsilon_{t} \\
E\left(\varepsilon_{t}\right)=0, \operatorname{Var}\left(\varepsilon_{t}\right)=\sigma_{\varepsilon}^{2}, E\left(\varepsilon_{t} \varepsilon_{s}\right)=0, s \neq t \\
E x_{s} \varepsilon_{t}=0, \forall s<t
\end{array}\right.
$$

The process of establishing the model:(obtaining the observed sequence value, stationary test, difference operation, variables test, fitting ARMA model, analysis result)like Fig. (2). Non-stationary sequence modeling flowchart.

The application of the model and the corresponding data processing: For the China disabled people's understanding of the most important thing of health problems, we make statistics from the survey of 501 people and we can know the concern of the disabled are: diet, health care, physical exercise these aspects. The importance of it is shown in Table 2.

Table 2. Disabled people's understanding of the most important thing of health problems.

\begin{tabular}{|c|c|c|}
\hline $\begin{array}{c}\text { Disabled people's Understanding } \\
\text { of the Most Important thing of } \\
\text { Health Problems }\end{array}$ & Number & Percentage \\
\hline \hline Diet structure & 95 & $18.90 \%$ \\
\hline Health care & 280 & $55.90 \%$ \\
\hline Physical exercise & 126 & $25.20 \%$ \\
\hline
\end{tabular}

(Source: Cai Muyong etc. the results of the questionnaire)

According to the above data, we make a pie figure shown in Fig. (3).

It can be seen from the above analysis, as for the physical health of Chinese disabled people, the most one they focus on were the health care, $25.2 \%$ of people pay attention to physical exercise, which is relatively small, so cause that the base of the disabled in China is large, but overall the number of people to participate in sports can not increase.

We discuss the purpose of Chinese disabled people's participating in the national fitness movement, including (to keep fit, to disease rehabilitation, entertainment, social intercourse, self-reliant, manifest its value, relieve pressure, other) and carry on the data analysis. The statistical results are shown in Table 3.

According to the above data, we make a pie figure shown in Fig. (4).

It can be seen from the above analysis that Chinese disabled people's participating in national fitness movement mainly focused on the purpose of strengthening the body, which occupied $32 \%$ of the total. This shows that the purpose

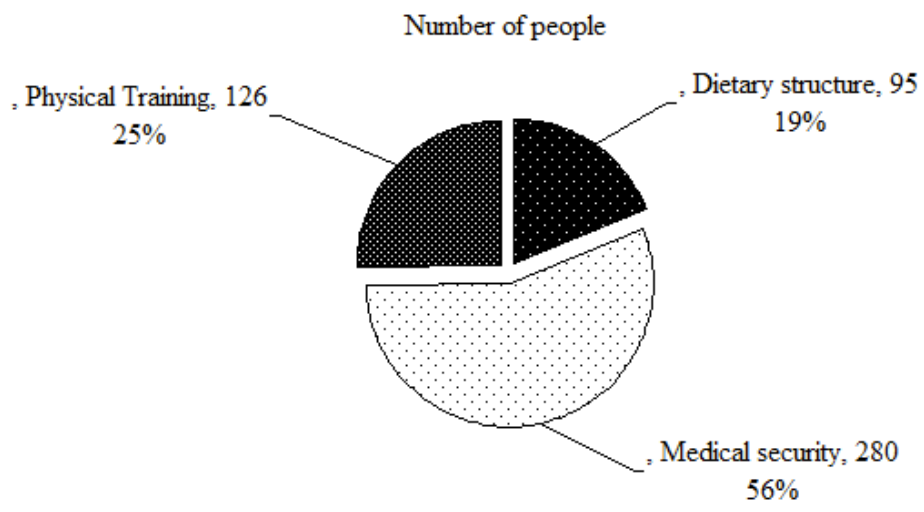

Fig. (3). Disabled people's understanding of health the most important question. 


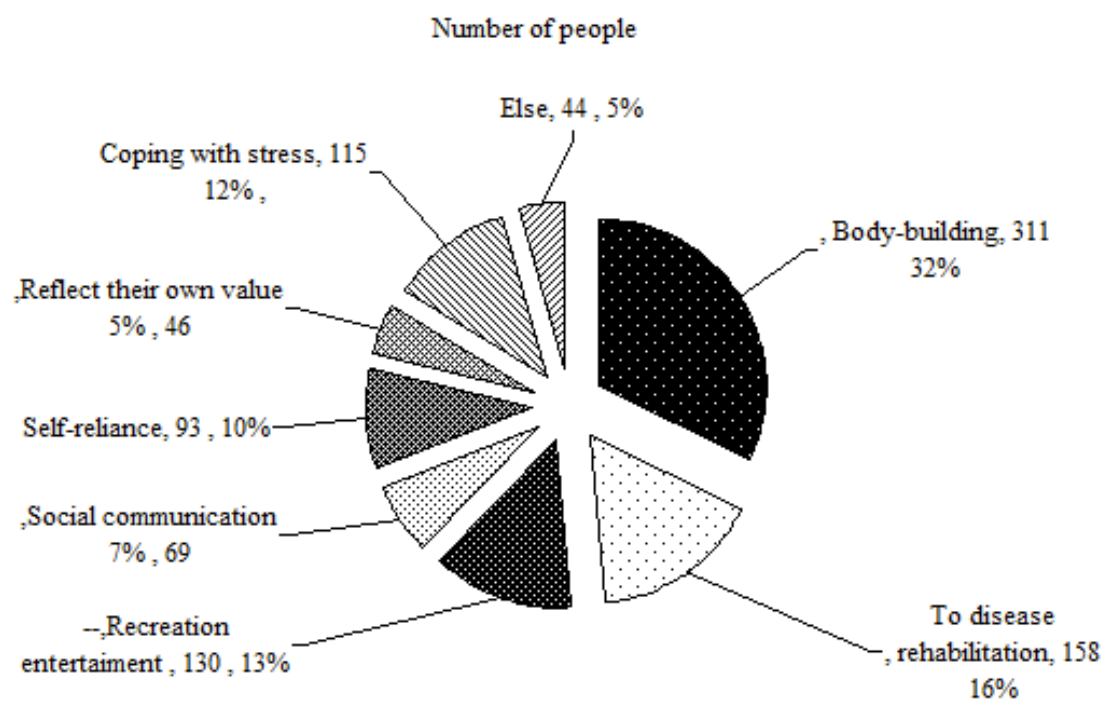

Fig. (4). The purpose of the disabled in our country to participate in the national fitness campaign.

Table 3. The purpose of the Chinese disabled people to participate in national fitness sports.

\begin{tabular}{|c|c|c|}
\hline Purpose & Number & Percentage \\
\hline \hline Strong the body & 311 & $62.10 \%$ \\
\hline Rehabilitate disease & 158 & $31.50 \%$ \\
\hline Entertainment & 130 & $26.00 \%$ \\
\hline Social interaction & 69 & $13.70 \%$ \\
\hline $\begin{array}{c}\text { Free-standing self- } \\
\text { improvement }\end{array}$ & 93 & $18.50 \%$ \\
\hline Reflect their own value & 46 & $9.10 \%$ \\
\hline To relieve stress & 115 & $22.90 \%$ \\
\hline Other & 44 & $8.80 \%$ \\
\hline
\end{tabular}

(Source: Cai Muyong etc. the results of the questionnaire) of Chinese disabled people's participating in physical exercise is very clear.

The structure of the disabled culture degree that comparing with the nationals'. It is shown in Table 4.

As can be seen from the above Table 4, Chinese disabled people's cultural level is generally low, the record of formal schooling of above of university is less than $1 \%$, and are mostly in the illiterate or semiliterate state. So we suggest that our government should pay more attention to the education of disabled people through the above survey, which can make Chinese disabled people receive a good education.

The main factors that influencing the Chinese disabled people's participating in the activities of the national fitness analysis, the results are shown in Table 5.

According to the above data, we make a pie figure shown in Fig. (5).

Corresponding to the above data and combined with the disabled people's understanding of the most important

Table 4. The structure of the disabled culture degree that comparing with the nationals'.

\begin{tabular}{|c|c|c|c|c|c|}
\hline & $\begin{array}{l}\text { The Number of the } \\
\text { Country (Ten Thou- } \\
\text { sand) }\end{array}$ & $\begin{array}{l}\text { The Percentage of the } \\
\text { Total Population }\end{array}$ & $\begin{array}{c}\text { The Number of the } \\
\text { Disabled (Ten Thou- } \\
\text { sand) }\end{array}$ & $\begin{array}{c}\text { The Percentage of the } \\
\text { Disabled }\end{array}$ & $\begin{array}{l}\text { The Percentage of the } \\
\text { Disabled Comparing with } \\
\text { the Total Population }\end{array}$ \\
\hline Total & 106793 & & 5164 & & 4.83 \\
\hline College and above & 947 & $0.88 \%$ & 15 & $0.29 \%$ & 1.58 \\
\hline High school degree & 7494 & $6.99 \%$ & 15 & $1.73 \%$ & 0.2 \\
\hline Junior high school degree & 22838 & $21.32 \%$ & 330 & $6.39 \%$ & 1.44 \\
\hline $\begin{array}{c}\text { The elementary school } \\
\text { level }\end{array}$ & 38683 & $36.11 \%$ & 1301 & $25.19 \%$ & 3.36 \\
\hline $\begin{array}{l}\text { Illiteracy semiliterate } \\
\text { (above } 6 \text { years old) }\end{array}$ & 25039 & $23.45 \%$ & 3300 & $63.9 \%$ & 13.18 \\
\hline $\begin{array}{l}\text { Illiteracy semiliterate } \\
\text { (above } 12 \text { years old) }\end{array}$ & 22056 & $20.56 \%$ & 3136 & $60.73 \%$ & 14.21 \\
\hline
\end{tabular}


Table 5. The main factors that influencing the Chinese disabled people's participating in the activities of the national fitness.

\begin{tabular}{|c|c|c|}
\hline $\begin{array}{l}\text { The Main Factors that Influencing the Chinese Disabled People's Participating in the } \\
\text { Activities of the National Fitness }\end{array}$ & Number & Percentage \\
\hline It never occurred to exercise because there is no guarantee of the basic life & 97 & $19.30 \%$ \\
\hline unable to move freely & 175 & $35.00 \%$ \\
\hline Family does not support & 14 & $2.80 \%$ \\
\hline Afraid of people's joke & 44 & $8.80 \%$ \\
\hline There is no necessary sports place or exercise equipment for the disabled & 128 & $25.50 \%$ \\
\hline The sports place is far from home & 58 & $11.50 \%$ \\
\hline The exercise equipment is not suitable & 30 & $6.00 \%$ \\
\hline Afraid of exposing their physical defects in public. & 38 & $7.50 \%$ \\
\hline Lack of professional guidance consultants specialized books & 121 & $24.10 \%$ \\
\hline No organization for the disabled to exercise & 142 & $28.30 \%$ \\
\hline No suitable sport project & 77 & $15.40 \%$ \\
\hline No fee & 98 & $19.50 \%$ \\
\hline No time & 134 & $26.70 \%$ \\
\hline Others & 26 & $5.20 \%$ \\
\hline
\end{tabular}

Table 6. The index statistics of Chinese disabled population in recent five years.

\begin{tabular}{|c|c|c|c|c|}
\hline Time & $\begin{array}{c}\text { Activities at the Provincial } \\
\text { Level (Place) }\end{array}$ & $\begin{array}{c}\text { Activities at Municipal } \\
\text { Level (Places) }\end{array}$ & $\begin{array}{c}\text { The national Fitness } \\
\text { Rehabilitation Projects (a) }\end{array}$ & $\begin{array}{c}\text { Cities Disabled Athletes } \\
\text { (m) }\end{array}$ \\
\hline \hline 2009 & 113 & 776 & 48 & 24069 \\
\hline 2010 & 126 & 629 & 40 & 30523 \\
\hline 2011 & 142 & 1455 & 56 & 25935 \\
\hline 2012 & 156 & 709 & 75 & 27879 \\
\hline 2013 & 169 & 857 & 80 & 49507 \\
\hline
\end{tabular}

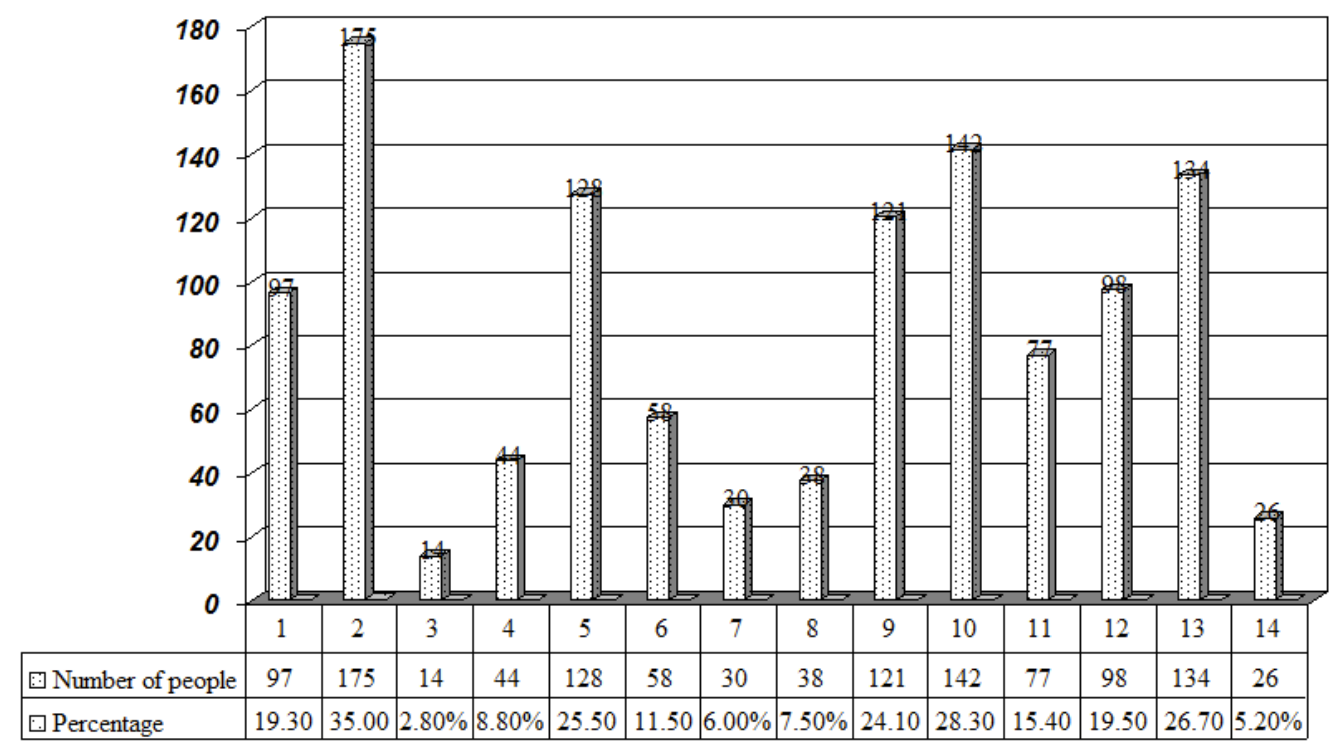

Fig. (5). The main factors influencing the Chinese disabled people to participate in the activities of the national fitness. 


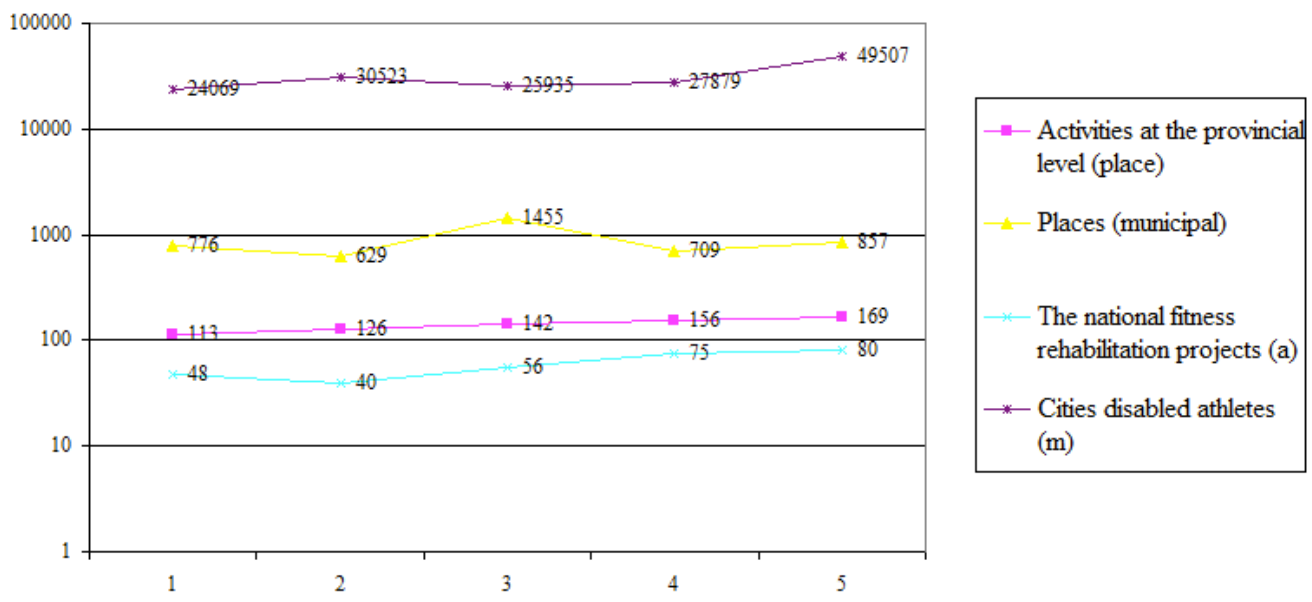

Fig. (6). Time according to the sequence analysis results.

question of health problems, the purpose of Chinese disabled people to participate in national fitness movement, the comparison of the structure of the disabled culture degree, we carry on the time series analysis of the main factors that influencing the Chinese disabled people's participating in the activities of the national fitness and so on these factors. It is shown in Fig. (6).

From the above data and time analysis, we can see the regulation that the activities at the provincial level, municipal activities, and the number of national rehabilitation exercise, cities disabled athletes; all of these have changed over time Table 6.

According to the time series analysis we know that pink line represents tendency, the green line represents seasonal cycle, the blue line represents stochastic. It is shown in the following Fig. (7): The decomposition of the time series data contrast figure:

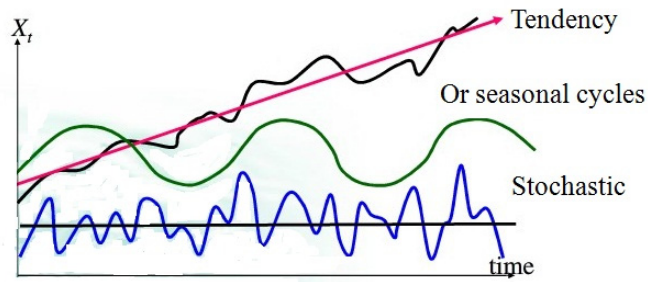

Fig. (7). The decomposition of the time series data contrast figure.

According to Fig. (7) and combined with Fig. (6), we can see that cities disabled athletes, the activities at the provincial level and the number of national rehabilitation exercise have an increasing tendency with the change of time, however the municipal activities change with the seasonal cycles.

Results analysis: Through the above time sequence analysis results, we can find that the management of Chinese current municipal activities need to be strengthened, to make it better serve the disabled, we should optimize Chinese disabled sports competition management mode in view of the above situation, including CDPF, Group of the state sport general administration department, China's Olympic sports management center for the disabled, National team, Different provinces DPF, the training base. The result is shown in Fig. (8).

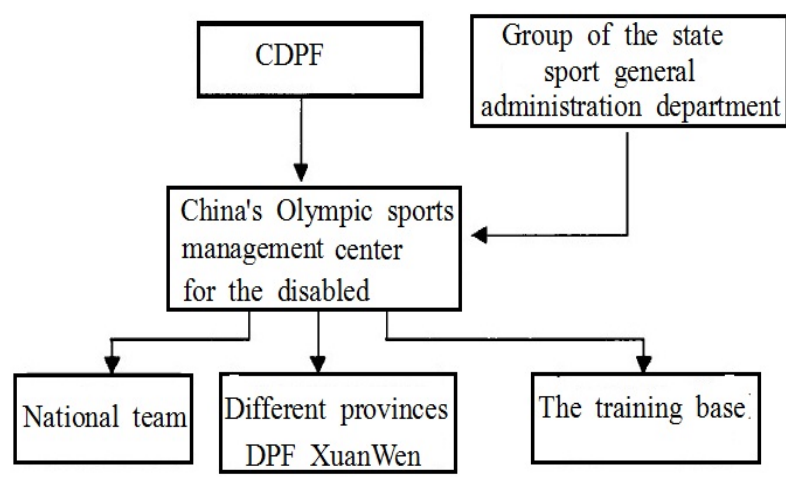

Fig. (8). The China's sports competition management mode for the disabled.

\section{CONCLUSION}

Comparing with western developed countries, the development of competitive sports for the disabled in China started relatively late, so the foundation is still very weak, which leads to the situations that the projects, the number of entries, and the inexperienced joining are all less than others in Paralympics, and the much of the competitors are new athletes, so called " more less than 3, more than 1" status quo.

Through the current situation, we analyze: the disabled people's understanding of most important question of health problems, the purpose of Chinese disabled people to participate in national fitness movement, the structure of the disabled culture degree comparing with the whole country, the main factors that influencing the Chinese disabled people to participate in the activities of the national fitness and so on. Through these, we get the conclusions that: we need to strengthen the management of the activities places of municipal disabled people, to make it better serve the disabled, and then optimize management mode of the Chinese disabled people's sports competition, and make it better manage local disabled peoples' federation.

\section{CONFLICT OF INTEREST}

The author confirms that this article content has no conflict of interest. 


\section{ACKNOWLEDGEMENTS}

Declared none.

\section{REFERENCES}

[1] C. Po, Q. Zhong-Mei, Y. Ying, and X. Chong-De, "Correlation analysis of current situation of regional athletics sports development and society population structure in china," J. Beijing Sport. Univ., vol. 30, no. 12, pp. 1610-1613, 2007.

[2] G. Hong, "Summary on chinese sports population research since 1980s,” China. Sport. Sci. Technol., vol. 43, no. 3, pp. 36-40, 2007.
[3] L. Hong, X. Hai-hong, and F. Wu-long, "Sociological analysis of comparison of chinese population with the sports population of chinese," J. Xi'an Inst. Phys. Educ., vol. 24, no. 4, pp. 25-28, 2007.

[4] M. Zhi-wen, and Q. Chun-lin, "Sociological analysis of contemporary Chinese sports population structures," J. Phys. Educ., vol. 13, no. 1, pp. 119-121, 2006.

[5] X. Huan-yu, and F. Li, "Concept classification and statistical criteria of sports population," Sports. Sci. Res., vol. 26, no. 1, pp. 7-10, 2005.

[6] Y. De-yi, "Development of sports for all under circumstance of building well-off society," J. Wuhan Inst. Phys. Educ., vol. 40, no. 1, pp. 15-19, 2006.

Received: June 10, 2015

Revised: July 29, 2015

Accepted: August 15, 2015

(c) Hong Luo; Licensee Bentham Open.

This is an open access article licensed under the terms of the (https://creativecommons.org/licenses/by/4.0/legalcode), which permits unrestricted, noncommercial use, distribution and reproduction in any medium, provided the work is properly cited. 